\title{
NOS CAMINHOS COM OS DOCENTES E AS CRIANÇAS DA BAIXADA FLUMINENSE: FORMAÇÃO, RESPONSABILIDADE E RESPONSIVIDADE
}

\author{
Elizabeth Orofino Lucio ${ }^{\mathrm{i}}$
}

\begin{abstract}
Resumo: Este texto apresenta o registro da construção de um coletivo docente que engloba a formação inicial e continuada de professores no Instituto Multidisciplinar da Universidade Federal Rural do Rio de Janeiro. O diálogo entre a tríade: estágio curricular na formação de professores, discursos e práticas educativas na Educação Infantil e o lugar da leitura e da escrita na formação docente nos permite indagar sobre as especificidades das experiências docentes e seu entendimento sobre a infância. Ademais, no caminho dessa problematização, questiona-se a forma como o estágio curricular adentra a prática pedagógica universitária por meio de uma pesquisa-formAÇÃO. Por fim, o texto provoca-nos a pensar a fotografia como potencial formativo e investigativo, que une vida-arte-conhecimento.
\end{abstract}

Palavras-chave: Licenciatura; Educação Infantil; Ensino Fundamental; Formação Docente; Fotografia; Leitura e Escrita.

\section{EN LOS CAMINOS CON LOS DOCENTES Y LOS NIÑOS: LA FORMACIÓN, LA RESPONSABILIDAD Y LA RESPONSIVIDAD}

Resumen: Este artículo presenta el registro de la construcción de un colectivo de enseñanza que abarca la formación inicial y continua de los profesores en el Instituto Multidisciplinario de la Universidad Federal Rural de Río de Janeiro. El diálogo entre la tríada de prácticas en la formación de profesores, discursos y prácticas educativas en la educación infantil y el lugar de la lectura y la escritura en la formación del profesorado nos permite indagar sobre los detalles de las experiencias de enseñanza y su comprensión de la infancia. Por otra parte, la trayectoria de este cuestionamiento, se pregunta cómo el periodo de prácticas entra en la práctica de la enseñanza universitaria a través de la investigación, la formación. Por último, el texto nos lleva a pensar en la fotografía como potencial formativo y de investigación, que combina los conocimientos, la vida el arte.

Palabras clave: Licenciatura; Educación Infantil; Enseñanza Fundamental; Formación del Profesorado; Fotografía; Lectura y Escritura.

\section{Introdução}

Educar como caminhar. Encontrar o próprio passo, o próprio peso e a própria leveza, a breve e fugaz medida dos átomos, as circunferências e as páginas escritas ou ainda em branco.

(Carlos Skliar) 
Esta escritacaminho pretende ser, sobretudo, registro da história de construção de um coletivo docente que se integra ao cotidiano de minha docência universitária no Instituto Multidisciplinar de Nova Iguaçu da Universidade Federal Rural do Rio de Janeiro (IM/UFRRJ).

Primeiramente, gostaria de registrar que se faz necessário explicitar, ainda, o sentido das palavras escrita e caminho, pois a palavra é uma parte da realidade material, "tecida a partir de uma multidão de fios ideológicos e serve de trama a todas as relações sociais em todos os domínios" (BAKHTIN; VOLOCHINOV, 1992, p. 41). Na perspectiva bakhtiniana, a palavra é um signo ideológico, marcado por valores de uma época, portanto signo ideológico de uma posição social e histórica.

A palavra caminho é usada aqui no sentido de rumo, direção e escrita, no sentido de escrita com assinatura, acompanhada de atenção e o empenho em favor dos docentes e das crianças da Baixada Fluminense, em um contexto histórico ${ }^{\mathrm{ii}}$ em que docentes lutam por melhores condições de trabalho, contra a privatização e o desmonte da escola pública, defendem pedagógica e politicamente concepções que não "interditem as formas linguísticas e os sujeitos" (GERALDI, 2010, p. 61), sendo necessário contar palavras, ou seja, trazer à existência palavras de futuros docentes e professores em exercício e levá-las em conta. Considerá-las, divulgá-las, revelá-las, propagá-las, proferi-las. Essas palavras, principalmente dos docentes e futuros docentes da Baixada Fluminense que, por meio da existência do Instituto Multidisciplinar e do Plano Nacional de Formação de Professores (PARFOR), integram um tempo histórico de possibilidades (FREIRE, 1996, p.10) em uma região marcada pela violência "Dos Barões ao extermínio" (ALVES, 2003).

A estrada bakhtiniana que continuará a ser trilhada no coletivo docente Caminhos intitula o presente artigo No caminho com os docentes e as crianças da Baixada Fluminense: formação, responsabilidade e responsividade. É importante destacar que o Instituto Multidisciplinar da Universidade Federal Rural do Rio de Janeiro constitui-se referência nacional brasileira, primordialmente na Região da Baixada Fluminense, em razão dos estudos que fomentam possibilidades de busca de novos sentidos da vida que pulsa (MINAYO, 2007, p. 72) na Baixada, possibilitando a pesquisa-formAÇÃO que, embrenhada em um contexto social e político complexo, permite-nos olhares sobre/para as crianças e os docentes, alunos das classes populares da Educação Infantil, do Ensino Fundamental e da Universidade de uma grande metrópole brasileira, abrindo perspectivas autorais, autônomas e emancipadoras. 
Essas perspectivas marcam minha inserção como docente no Instituto Multidisciplinar da UFRRJ, em março de 2015, fazendo-me pensar e aprofundar meus estudos nas políticas contemporâneas de formação docente, engendradas por e em função do viés gerencialista na Educação e suas práticas educativas acríticas, e a necessidade de uma formação contra-palavra (LUCIO, 2016), suas possibilidades teóricas e didático-pedagógicas, mas, sobretudo, éticoestético-políticas na formação e no trabalho docente.

O coletivo docente ${ }^{\mathrm{iii}}$ Caminhos pretende consolidar conhecimentos no campo da formação de educadores e desenvolvimento profissional docente, buscando compreender os desafios contemporâneos que perpassam as práticas sociais e educacionais, a partir dos estudos da linguagem, apoiados em Mikhail Bakhtin, tendo em vista as tensões singulares da atualidade.

Essas tensões fazem-me escrever como ação política responsável e responsiva ${ }^{\text {iv }}$, constatando que é preciso refletir e construir novas práticas formativas docentes e práticas educativas na Universidade.

Justiça e Ousadia marcam, também, as inquietações que pervagam este caminho que registra uma experiência em processo no IM/ UFRRJ e que se materializa nas seguintes questões: como os problemas de ordem econômica, sociocultural e política, nos quais se originam a violência e o fenômeno ideológico da "criminalização da pobreza", reverberam-se e desdobram-se nas escolas públicas da Baixada Fluminense e no IM/UFRRJ? O que isso tem a ver com a crença de que os alunos da Educação Infantil e da Universidade, oriundos de classes populares, são impotentes ou incapazes de apropriação e inserção na cultura da escrita, no universo letrado? Como fazer para que as marcas do fenômeno ideológico do preconceito linguístico e suas reverberações não adentrem o espaço acadêmico? De que forma planejar um estágio curricular de modo a integrar um espaço em que teorias e práticas em interconexão proporcionem a construção da aprendizagem sobre a educação escolar, em um contexto histórico marcado pela implementação da Lei Federal 11.274 (Brasil, 2006) e pela discussão acerca da obrigatoriedade escolar para pessoas de 4 a 17 anos (PL 414/2008; PL 06755/2010), aliando o exercício da docência e a pesquisa?

A ousadia fez-me partilhar questões sobre como alinhavar reflexões sobre as infâncias, as culturas e a cultura letrada na formação de docentes em exercício e futuros docentes marcados fortemente pela ideologia do fracasso e da dificuldade com a escrita. Assim, iniciei o planejamento de meu trabalho na disciplina Prática de Ensino e Estágio Supervisionado na 
Educação Infantil, através do elo professora-pesquisadora (ESTEBAN; ZACCUR, 2002), vidaarte-conhecimento (BAKHTIN,1926) e exotopia e alteridade (BAKHTIN,1992,2003).

Dessa forma, fez-se o caminho que me conduz à proponente de um coletivo docente, no caminho que se fez caminhando junto aos futuros docentes e docentes em exercício do PARFOR que adentram o IM/UFRRJ e "agarram com unhas e dentes"v a formação universitária e lutam, esperançosamente, contra as impossibilidades que lhes foram impostas como cidadãos da Baixada Fluminense.

\section{Caminhos do coletivo docente}

O projeto do coletivo docente "Nos caminhos com os docentes e as crianças da baixada fluminense: formação, responsabilidade e responsividade" faz parte do Instituto Multidisciplinar de Nova Iguaçu da Universidade Federal Rural do Rio de Janeiro, que une alunas e alunos do PARFOR e dos demais processos seletivos em uma única turma.

Neste projeto, interessa-me especificamente analisar como a formação docente vivida dentro do IM/UFRRJ, nas disciplinas Prática de Ensino e Estágio Supervisionado na Educação Infantil, articula práticas educativas no sentido de compreender as especificidades das experiências dos futuros docentes e seu entendimento sobre as crianças envolvidas no processo relacional entre a Educação Infantil e o Ensino Fundamental.

Durante minha atuação docente no IM/UFRRJ, na disciplina Prática de Ensino e Estágio Supervisionado na Educação Infantil no período 2015-2, em uma turma que englobava futuros docentes e docentes em exercício na Educação Infantil, realizei o planejamento e o trabalho do estágio supervisionado por meio de visitas às instituições de Educação Infantil, privilegiando fotografias que eram produzidas nas visitas como potencial formativo e investigativo, além do relatório de estágio.

Elegendo para a pesquisa-formAÇÃO as fotografias apresentadas e socializadas durante as aulas e organizadas na primeira exposição fotográfica da Educação Infantil no IM, realizada no dia 29 de outubro de 2015, intitulada “A Educação Infantil que eu vejo: vivências e práticas" e na segunda exposição, concretizada em 27 de junho de 2016, nomeada "Pelos caminhos com as crianças da Baixada Fluminense", desafiei-me, em conjunto com os docentes, a investigar vivências, práticas, saberes docentes e olhares sobre a infância, implícitos nessas 
fotografias, socializadas nas aulas e organizadas de forma autoral pelas alunas, para exposição, com o fim de refletir sobre a formação vivida e praticada nesse processo.

As fotografias e a exposição fotográfica apresentam possibilidades para pensarmos e articularmos a complexidade da formação e o percurso investigativo desse processo de estudo, abrindo horizontes para pensarmos outro modo de fazer outra ciência: uma heterociência (BAKHTIN, 1926,2003; MELLO, 2013) que una vida-arte-conhecimento e que se funda em um princípio estético, compreendendo as fotografias e a exposição fotográfica como "um modo de dizer o conhecimento por meio da linguagem" (GERALDI, 2011), especificamente a linguagem fotográfica.

\section{Aulasencontro: movimentos a contrapelo}

Como professora universitária, formadora de professores e pesquisadora bakhtiniana, acredito no poder das palavras e na possibilidade de escrever e contar a história a contrapelo. Pelo discurso e pela ação, os homens podem distinguir-se e não serem apenas diferentes, pois é com palavras e atos que nos inserimos no mundo humano (ARENDT, 2005, p. 189) e essa inserção é a morte do velho e o nascimento do novo, categorias carnavalescas bakhtinianas que remetem a um mundo "novo". Assim, realizo uma analogia para defender uma formação humana alicerçada no ato, em que a experiência, a escuta dialógica, a atitude responsável e responsiva diante da palavra do outro favoreça a palavra própria.

Busco, com esse coletivo, movimentos a contrapelo (BENJAMIN, 1994) que dialoguem com os estudos pós-coloniais e colabore para a gestação da criação de um processo de formação inicial e continuada de professores em que os docentes sejam protagonistas, autores heróis $^{v i}$ (BAKHTIN, 1992, 2003) da formação e que suas 'vozes' próprias ecoem em novos Encontros de formação inicial e continuada, por via da extensão universitária, que valorizem a escuta como essencial para uma educação que produza novos sentidos e efetive uma perspectiva enunciativa discursiva (ANDRADE, 2011). Tal perspectiva de formação vai ao encontro de um processo de valorização, compartilhamento-publicização (LUCIO,2016) dos saberes docentes, qualificando experiências na escola pública da Baixada Fluminense como legítimos. 
Trago a palavra compartilhamento hifenizada com publicização para atender ao propósito de marcar uma posição ético-política e epistemológica de configuração mais ampla do que aquela que geralmente subjaz ao uso do termo em contextos de formação docente, centrada numa lógica utilitarista, pragmática, de funcionalidade do gesto de compartilhar, circunscritos na simetria dos sujeitos: professores universitários falando para futuros professores e professores, diretores para diretores, em movimentos endógenos na escola.

No confronto das múltiplas vozes da formação, o futuro professor e o professor em exercício, quando não está na posição de espectador aprendente, poucas vezes é autor e coautor na formação. Trata-se de uma valorização das contribuições dos sujeitos inseridos no cotidiano escolar, por via do estágio curricular, mas que não basta para legitimar os docentes e futuros professores na esfera do discurso pedagógico. A categoria compartilhamento-publicização está diretamente relacionada ao horizonte social bakhtiniano que, por um lado, ajuda a superar a lógica do mercado da formação, viabilizado pela universitarização e, por outro, rompe com a visão endógena de formação centrada na escola para a escola. Não se trata de negar o legado da universidade na produção do conhecimento no campo pedagógico, mas de tomá-la como potencializadora da publicização do discurso docente, à medida que se constitua o horizonte social, o espaço-tempo compreendido em uma relação verbal, ou seja, o espaço-tempo da enunciação (GEGE, 2009, p. 58), o qual orienta os sujeitos quanto aos valores construídos na interação na formação, propondo assunção de posicionamentos.

As Aulasencontros (LUCIO, 2016) trouxeram à tona diversos desafios que perpassam o cenário educacional brasileiro, entre eles "brechas" entre a Educação Infantil e a Escola Básica, por meio de fotografias que registram práticas docentes com crianças da Educação Infantil, envoltas em atividades escolarizadas de leitura e escrita, assim como docentes e futuros docentes, "escritores apagados" diante do desafio da escrita, mostrando-nos que é necessário construir e buscar formas de formação-atuação.

Assim, entendo que as Aulasencontros no IM/UFRRJ, por meio das quais foi possível realizar o primeiro momento desse coletivo, constituíram-se como instância importante, por considerar os professores da escola básica, presentes no PARFOR, e futuros docentes como sujeitos que constroem conhecimentos, pois os principais recursos da Educação são as pessoas, os saberes e as experiências mobilizadoras. (CANÁRIO, 2014)

Alinhavo, assim, o contexto do coletivo docente e passo a dialogar com alguns aportes teóricos para, inicialmente, abordar a temática fotografia, formação docente e heterociência. 
Em seguida, considero relevante apresentar a questão da implementação da Lei Federal 11.274 (Brasil, 2006) e das portarias (PL 414/2008; PL 06755/2010), em diálogo com a Resolução CNE/MEC 02/2015. Por fim, apresento como concebo a linguagem articulada à dimensão sociocultural em que estão inseridos os sujeitos, ou seja, o caminho do IM/UFRRJ como uma Universidade que na atualidade possui responsabilidade com a Educação Básica e a formação de professores da Baixada Fluminense, isto é, uma Instituição socialmente responsável pela construção de um percurso de estudo comprometido com a busca de superação dos problemas sociais e com a produção de conhecimentos que gerem novos percursos em contextos e situações específicas da formação docente.

\section{Formação docente, fotografia e heterociência}

A ação principal desse coletivo é a realização de aulasencontros que se constituem em

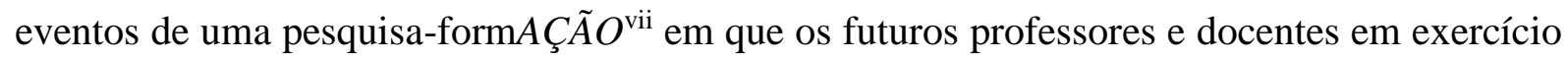
são constantemente convidados a falar e escrever sobre suas práticas no relatório de estágio.

Inicialmente, havia uma grande socialização por parte dos integrantes da turma por meio da oralidade, mas, ao serem convidadas a escrever, as alunas integrantes da turma sempre mostravam resistência, utilizando argumentos que se embasavam ora na responsabilização do "fracasso escolar" pela trajetória na escola pública, ora pela complexidade entre a universidade e a escola básica, o que podemos ratificar por meio dos enunciados abaixo, repletos de intencionalidades:

\footnotetext{
"Minha trajetória de estudante foi bem dificil, porque tinha dificuldade de aprender a ler e isto foi muito ruim." (Fragmento de questionário diagnóstico respondido pela aluna Fabiana Rosa do IM/ UFRRJ, professora da Rede Municipal de Queimados, apresentado como trabalho inicial da disciplina Prática de Ensino e Estágio Supervisionado na Educação Infantil, realizado no segundo semestre de 2015.)

"Fiz as séries iniciais com bastante dificuldade. Ensino Médio não terminei no tempo certo, parei várias vezes. Fiz o curso de formação de professores em um ano. Não é fácil escrever. "(Fragmento de questionário diagnóstico respondido pela aluna Josely Ramos do IM/ UFRRJ, professora contratada da Rede Municipal de Japeri, apresentado como trabalho inicial da disciplina Prática de Ensino e Estágio Supervisionado na Educação Infantil realizado no segundo semestre de 2015.)

"Sempre estudei em escola pública." (Fragmento de questionário diagnóstico respondido pela aluna Priscila Britto do IM/ UFRRJ, professora da Rede Municipal de Austin, apresentado como trabalho inicial da disciplina Prática de Ensino e Estágio Supervisionado na Educação Infantil, realizado no segundo semestre de 2015.)

Um breve desabafo...Inicio falando sobre a universidade, vejo que de fato aquilo que aprendemos está longe do que praticamos. Hoje depois de um certo tempo me tornei novamente aluna e posso perceber que a escola durante muito tempo não mudou, embora o "discurso" teórico seja outro. Às vezes me pergunto se não seria bom ter permanecido apenas aluna, seria bem mais fácil. Lidar com essa dualidade me incomoda demais, assim como escrever!! (Fragmento de questionário diagnóstico realizado pela aluna Ana Cristina do IM/ UFRRJ, professora
} 
Alicerçando o trabalho com a linguagem como produção discursiva das professoras e futuras docentes, encontrei nas fotografias um dispositivo de formação (CANÁRIO, 2001) que, somando-se aos conhecimentos existentes, é um dispositivo de trocas de saberes e construção conjunta de conhecimentos e novas práticas pedagógicas.

O encontro com as fotografias, após a primeira visita às instituições de Educação Infantil, planejada no Estágio Curricular, fez com que eu alterasse minha atuação pedagógica. A posição de simetria ${ }^{\text {viii }}$ (SOBRAL, 2015) que vivenciava e a relação dialógica, em que docente e alunas são sujeitos que falam (BAKHTIN, 2003), que podem refletir, aprender $e$ ressignificar-se (FREITAS, 2007, p. 27-28), conduziram-me à reflexão de que as fotografias permitiam a desinvibilização de saberes e fazeres das docentes e das crianças da Baixada Fluminense, além de possibilitar uma ponderação importante sobre a supremacia da escrita numa sociedade grafocêntrica e com multiletramentos (ROJO e MOURA, 2012).

Acolher outras escritas, escritas semióticas, foi um movimento necessário no sentido de (re)conhecer as maneiras de registro e produção de discurso das docentes alunas que não se sentiam "autorizadas" a escrever e que, na complexidade do percurso de docência que se tornou investigação, abriu possibilidades para pensar um outro modo de fazer pesquisa com os futuros professores e docentes, lendo as imagens e a experiência ${ }^{i x}$ (LAROSSA, 2015) visual, dialogando com elas e com seus autores, considerando cada produção discursiva enunciada, durante a Aulasencontro, um ato de cocriação, coparticipação, no ato de narrar.

Contudo, é preciso reconhecer nas Aulasencontro a importância de não perder de vista o lugar exotópico que devia ocupar, pensando sempre que a exotopia é algo por conquistar e, na batalha, é mais comum perder a pele do que salvá-la (BAKHTIN, 1992, p. 35), é transporme da linguagem interna de minha percepção para a linguagem externa da expressividade externa e entrelaçar-me por inteiro, sem resíduo, na textura plástico-pictural da vida, enquanto homem entre outros homens, enquanto herói entre outros heróis (BAKHTIN, 1992, p. 50-51).

Concomitantemente ao último ano de meu doutorado, implicava-me uma investigação, gestada no cotidiano da universidade, a qual vislumbra a construção de um coletivo docente como uma ação compromissada com a formação e o desenvolvimento pessoal e profissional, procurando, por meio de uma epistemologia do sentido e da escuta (CANÁRIO, 2005, p.101) e da linguística da escuta (PONZIO, 2012, p.68), renunciar à produção de um discurso 
prescritivo de formação. Contudo, intenciono que este trabalho possa auxiliar os professores em suas ações futuras como pesquisadores de sua própria prática.

A fotografia, enquanto arte, representação da vida e do conhecimento, enquanto elo de interação de produção oral, visual e escrita, conduz-me a problematizar seu papel no processo formativo docente, pensando que estamos diante de uma documentação narrativa (SUÁREZ, 2007), pensada como

[...] una modalidad particular de indagación narrativa e interpretativa que pretende reconstruir, documentar, tornar públicamente disponibles, tensionar y volver críticos los sentidos, comprensiones e interpretaciones pedagógicas que los docentes construyen, reconstruyen y negocian cuando [...] conversan entre colegas acerca de sus propias práticas educativas. [...] A través de ellas, los procesos de documentación narrativa llevados a cabo colaborativamente por docentes e investigadores se presentan como vías válidas para la reformulación, la ampliación y la transformación de la propia práctica docente que incursiona en lo inédito, en lo silenciado, en lo aún no descrito ni dicho.

Elegemos, assim, a fotografia didocente ${ }^{\mathrm{x}}$ (LUCIO, 2016), fotografias produzidas por futuros docentes e docentes no estágio curricular sobre a infância e as práticas pedagógicas da EI, como enunciados ${ }^{\mathrm{xi}}$ que contém uma narrativa possível dos conhecimentos tecidos entre a arte, a vida e o conhecimento, pensando como João Wanderley Geraldi (2011), o qual afirma que nem sempre o modo de dizer o conhecimento precisa ser tradicional, isso pode ser feito de várias formas, como por um filme, por imagens ou outros tipos de linguagem.

Na perspectiva bakhtiniana, a fotografia, objeto de estudo e estratégia metodológica da pesquisaform $A C ̧ \tilde{A} O^{\mathrm{xii}}$ a ser realizada neste estudo, é concebida como uma unidade de comunicação, como uma unidade de sentido, necessariamente contextualizada. Sendo assim, a fotografia não se constitui apenas por seus elementos semióticos internos (cor, foco, enquadramento de luz, entre outros), mas, também, por condições extraverbais da situação da qual se constitui.

Na obra Discurso na Vida e Discurso na Arte - sobre a Poética Sociológica, Voloshinov/Bakhtin (1981) afirma que o enunciado é composto por três fatores: (a) o horizonte espacial comum dos interlocutores; (b) a compreensão comum da situação por parte dos interlocutores e (c) a avaliação comum dessa situação. Assim, compreende-se que o enunciado e as condições sociais de sua enunciação constituem o processo de interação verbal, ou seja, o verbal (ou outro material semiótico) e o não-verbal (a dimensão social) que integram a situação. 
A fotografia como enunciado caracteriza-se por seus elementos semióticos internos e por suas particularidades de enunciação. Segundo Voloshinov/Bakhtin (1981, p. 190),

a situação extraverbal está longe de ser meramente a causa externa de um enunciado - ela não age sobre o enunciado de fora, como se fosse uma força mecânica. Melhor dizendo, a situação se integra ao enunciado como uma parte constitutiva essencial da estrutura de sua significação.

Considero, nesta pesquisa, que as fotografias didocentes (LUCIO, 2016), enquanto enunciados, à medida que são determinadas por seu horizonte temporal, espacial, temático e axiológico, constroem-se a partir da posição valorativa de seu autor e são tecidas por diversas dialogias.

Nesse movimento, as fotografias didocentes instigam-me a pesquisar sobre elas, buscando compreender os saberes e fazeres das crianças e dos docentes da Educação Infantil na Baixada Fluminense e, imersa nesse contexto, pergunto: a fotografia é uma documentação narrativa potente para a formação inicial e continuada de docentes? A fotografia corrobora para a formação do professor como pesquisador de sua prática? É possível reconfigurar o estágio curricular por meio do ato de fotografar? A experiência do ato fotográfico e da composição de exposição fotográfica, enquanto princípio estético integrante do processo formativo, contribui para o conhecimento do mundo, da criança e da docência na Educação Infantil? $\mathrm{O}$ ato fotográfico foi vetor da escrita verbal dos relatórios de estágio?

\section{Entre a lei, as portarias e a resolução: brechas curriculares}

Entendo que os processos formativos de professores são territórios em processo de constituição, permeados por tensões e disputas, tanto no plano político quanto no epistemológico. Dessa forma, faz-se necessário refletir sobre a contextualização da Educação a partir do século XXI e os marcos legais que entrelaçam a Educação Infantil e a formação de professores na licenciatura.

Em uma região marcada pelas desigualdades sociais como a Baixada Fluminense, um projeto de coletivo docente não pode deixar de se preocupar com a produção do conhecimento no campo dos processos formativos e com a questão das políticas que possam propor 
dispositivos de enfrentamentos destas desigualdades, no escopo do processo educacional diante de um contexto internacional e nacional em que

As políticas oficiais de avaliação do desempenho dos estudantes vêm fomentando desenhos curriculares, práticas pedagógicas e projetos de formação docente que demandam/ buscam uniformização e homogeneidade. $\mathrm{Na}$ perspectiva hegemônica, à aprendizagem se compreende/vê como um processo linear e progressivo, realizado por movimentos previsíveis, segundo modelos predeterminados. Os resultados e processos infantis que se distanciam dos padrões predefinidos frequentemente são tratados como dificuldades de aprendizagem, o que indica o não reconhecimento de sua qualidade (...). (ESTEBAN; SAMPAIO, 2012).

A ampliação do ensino fundamental para nove anos, por meio da Lei Federal 11.274 (BRASIL, 2006), e a discussão acerca da obrigatoriedade escolar para pessoas de 4 a 17 anos (PL 414/2008; PL 06755/2010), assim como a reformulação curricular prevista na Resolução CNE/MEC 02/2015, que modifica as Diretrizes Curriculares Nacionais para a formação inicial em nível superior, trazem questões para a pesquisa que triangulem a implementação da lei, a relação Educação Infantil e Ensino Fundamental e formação docente nas licenciaturas.

Segundo a minha perspectiva, os sujeitos envolvidos nesse processo, docentes, futuros professores e crianças e os contextos podem subsidiar o diálogo e a ampliação da compreensão das continuidades e/ou rupturas vividas na Educação Infantil e no Ensino Fundamental, pelas crianças e pelos docentes, ciente de que o desafio é estreitar a distância entre o que é proposto e as ações concretas.

As políticas educacionais, segundo Stephen Ball e seus colaboradores (BOWE; BALL; GOLD, 1992; BALL, 1994), merecem destaque por suas influências em diversos trabalhos no Brasil (MAINARDES; MARCONDES, 2009). Sua concepção pós-moderna da policy cycle approach ou "abordagem do ciclo de políticas" e o contexto do ciclo de políticas, denominados de contexto de influência, contexto da produção de texto, contexto da prática, contexto dos resultados/efeitos e contexto de estratégia política, apontam à necessidade de se articularem os processos macros e micro na análise de políticas educacionais, relacionando-os à interdependência, visão com a qual corroboro.

O caminho para concretização do discurso oficial e político de uma infância de direitos perpassa, sem dúvida, pela criação de dispositivos de formação concebidos em conjunto entre futuros docentes, professores ligados às instituições de EI e às universidades, lembrando que a 
formação acontece na produção de estratégias, de metodologias adotadas, havendo sempre construção do conhecimento e teorização do que ocorre na formação.

Aliar a concepção de formação docente à perspectiva da formação de adultos (CANÁRIO, 2014) é tratar a formação como um processo autogerido coletivamente, enfatizando sempre que o espaço universitário é composto de adultos e que as instituições de EI são uma organização social, ou seja, uma construção social feita por pessoas que não são "autômatas", ou seja, só é possível trabalhar com os contextos em que as pessoas estão e sentem-se implicadas e interventoras. Eis o nosso desafio ao propor a construção de um coletivo docente que aja entre as brechas das políticas oficiais, hegemônicas e colonialistas, de formação docente no IM/UFRRJ, que se integre, em um futuro próximo, à Rede de Formação Docente: Narrativas e Experiências (Rede Formad/UNIRIO/Brasil) e à Red de Formación Docente y Narrativa (Argentina).

\section{O IM/UFRRJ: a universidade que forma professores}

Os dez anos de criação do curso de Pedagogia no IM/UFRRJ marcam a consolidação dessa Instituição que, durante anos, dedicou-se aos estudos nas áreas das ciências agrárias e abriu seu espaço para a formação de docentes de diferentes áreas em cursos de licenciatura, como lócus de formação de professores na Baixada Fluminense.

Assinalo como singular o interesse por registrar e teorizar a vivência de uma formação que construiu a mudança de estratégias formativas por meio das inter-relações e interlocuções de futuros professores, professores da educação básica e de uma professora formadora pesquisadora universitária, sobretudo, quando a escola básica e a universidade entrecruzam-se na dialogia da formação docente que foi propiciada pela implementação do PARFOR no IM/UFRRJ.

A construção de um curso de Pedagogia em que caibam todos e todas (LINHARES,2014) é o alicerce do IM/UFRRJ e reafirmação da relação entre universidade e escola básica, integrando o ensino, a pesquisa e a extensão universitária, é o objetivo dessa proposta que pretende contribuir para o seu fortalecimento, ratificando, assim, que

a Universidade é um bem público e o local privilegiado da formação docente

e da produção do conhecimento no campo pedagógico, sendo a 
potencializadora da publicização do discurso docente, propondo novos horizontes sociais e uma nova assunção de posicionamentos. (LUCIO, 2016).

O objetivo é construir o coletivo docente que investige, por meio de fotografias, a formação docente vivida dentro do IM/UFRRJ, nas disciplinas Prática de Ensino e Estágio Supervisionado na Educação Infantil, procurando compreender as especificidades das experiências dos futuros docentes e professores em exercícios e seu entendimento sobre as crianças e as práticas docentes, envolvidas no processo relacional entre a Educação Infantil e o Ensino Fundamental.

\section{REFERÊNCIAS}

ANDERSON, Higor Leal. Fotografias docentes: saberesfazeres alfabetizadores narrados em espaçostempos de formação de professores(as). Dissertação de mestrado, Educação, UNIRIO, 2014.

ANDRADE, Ludmila Thomé de . Uma proposta discursiva de formação docente. In: Revista Práticas de Linguagem. Juiz de Fora, v. 1, n. 2, jul./dez. 2011. p. 87-98. Disponível em: <http://www.ufjf.br/praticasdelinguagem/files/2012/02/Fale-para-o-professor >. Acesso em: 01 fev. 2014.

ALVES, José Claudio Souza. Dos barões ao extermínio: uma história da violência na Baixada Fluminense. Duque de Caxias: APPH,CLIO, 2003.

AMARAL, Maria Cristina Fontes. Registros e avaliação na educação infantil: entrecruzando olhares para qualificar as práticas. Dissertação de mestrado, Educação, UFJF, 2014.

ARENDT, H. A Condição Humana. 10. ed. Rio de Janeiro: Forense Universitária,2005.

AMORIM, M. O pesquisador e seu outro: Bakhtin nas Ciências Humanas. São Paulo: Musa, 2004.

. Cronotopo e exotopia. In: BRAIT, B. (Org.) Bakhtin, outros conceitos-chave. São Paulo: Contexto, 2006, p. 95-114.

A contribuição de Mikhail Bakhtin: a tripla articulação ética, estética e epistemológica. In: FREITAS, M. T.; SOUZA, S. J.; KRAMER, S. Ciências Humanas e Pesquisa. Leituras de Mikhail Bakhtin. São Paulo: Cortez, 2007, p. 57-76. 
Para uma filosofia do ato: "válido e inserido no contexto". Disponível em:

<http://www.martinsfontespaulista.com.br/anexos/produtos/capitulos/579059>. Acesso em: 28 abr. 2013.

ARROYO, Miguel G.. O direito à educação e a nova segregação social e racial ? tempos insatisfatórios?. In: Educação em Revista, UFMG, v. 31, p. 15-47, 2015.

BAKHTIN, M. (VOLOCHINOV). Marxismo e filosofia da linguagem. São Paulo: Hucitec, 1992.

BAKHTIN, Mikhail. Estética da criação verbal. 4. ed. São Paulo: Martins Fontes, 2003.

Discurso na vida e discurso na arte. Tradução para o português, feita por Carlos Alberto Faraco e Cristovão Tezza de "Discourse in life and discourse in art - concerning sociological poetics", publicada em V. N. Voloshinov, Freudism, New York. Academic Press, 1976.

. Estética da Criação Verbal. São Paulo: Martins Fontes, 1992.2003.

Marxismo e Filosofia da linguagem. São Paulo: Hucitec, 2010.

Estética da Criação Verbal. SP: Martins Fontes, 2010.

2010.

Para uma filosofia do ato responsável. São Carlos/SP: Pedro \& João Editores,

A Cultura popular na Idade Média e no Renascimento: o contexto de

François Rabelais. São Paulo/Brasília: Hucitec/Editora Universidade de Brasília, 2008.

Palavra própria e palavra outra na sintaxe da enunciação: A palavra na vida e na poesia. Introdução ao problema da poética sociológica. São Carlos: Pedro \& João Editores, 2011.

BRASIL. Lei n. 11.274, 6 de fevereiro de 2006. Altera a redação dos Arts. 29, 30, 32 e 87 da Lei n. 9.394, de 20 de dezembro de 1996, que estabelece as diretrizes e bases da educação nacional, dispondo sobre a duração de 9 (nove) anos para o ensino fundamental, com matrícula obrigatória a partir dos 6 (seis) anos de idade. Diário Oficial da União, Brasília, DF, 7 fev. 2006. Disponível em: 〈www.senado.gov.br〉. Acesso em: 27 jul. 2015.

PL 414/2008/ PL 06755/2010. In.: PORTAL DA ATIVIDADE LEGISLATIVA.

Projetos e Matérias Legislativas. Brasília, 2010. Disponível em:

http://www25.senado.leg.br/web/atividade/materias/-/materia/ Acesso em: 28 de maio de 2016.

Resolução CNE/CP no 2, de $1^{\circ}$ de julho de 2015 - Define as Diretrizes Curriculares Nacionais para a formação inicial em nível superior (cursos de licenciatura, cursos de formação pedagógica para graduados e cursos de segunda licenciatura) e para a formação continuada. 
BRAIT, Beth. O discurso sob o olhar de Bakhtin. In: GREGOLIN, Maria do Rosário; BARONAS, Roberto (Orgs.). Análise do Discurso: as materialidades do sentido. 2. ed. São Carlos: Editora Claraluz, 2003.

CANÁRIO, Rui. O que é a escola? Porto: Porto Editora,2005.

CORSINO, Patrícia. Educação Infantil: cotidiano e políticas. Campinas: Autores Associados, 2009.

ESTEBAN, Maria Teresa; ZACCUR, Edwiges. A pesquisa como eixo de formação docente. In: _. (Orgs.). Professora-pesquisadora - uma práxis em construção. Rio de Janeiro: DP\&A, 2002.

ESTEBAN, Maria Teresa; SAMPAIO, Carmen Sanches. Diferença, alteridade e aprendizagem: desafios infantis ao saber docente. In: ENCONTRO NACIONAL DE DIDÁTICA E PRÁTICAS DE ENSINO - ENDIPE, XVI., Campinas, SP, 2012. Anais. Campinas, SP, 2012.

FORMOSINHO, João. A universidade e a formação de educadoras de infância: potencialidades e dilemas. In: MACHADO, Maria L.A. (Org.). Encontros e desencontros em educação infantil. São Paulo: Cortez, 2002.

FREIRE, Paulo. Pedagogia da Autonomia. São Paulo: Paz e Terra,1996.

FREITAS, Maria Tereza. A perspectiva sócio-histórica: uma visão humana daconstrução do conhecimento. In: FREITAS, M. T.; SOUZA, S. J.; KRAMER, S. (Orgs.). Ciências Humanas e Pesquisa. Leituras de Mikhail Bakhtin. São Paulo: Cortez, 2007.

GATTI, Benarderte A.. Formação inicial de professores para a educação básica: pesquisas e políticas educacionais. Est. Aval. Educ., São Paulo, v. 25, n. 57, p. 24-54, jan./abr. 2014.

GERALDI, João Wanderley; FREITAS, Maria Tereza. Bakhtin é o pano de fundo ao modelo neoliberal da Educação. In: Encontros Possíveis, UFJF, 2011. Disponível em: <www.ufjf.br/revistaa3/.../small_youblisher.com-183638-Revista_A3_01_20_24.pdf>. Acesso em: 23 de maio de 2016.

GERALDI, João Wanderley. Ancoragens: estudos bakhtinianos. São Carlos: Pedro \& João editores, 2010.

A aula como acontecimento. São Carlos: Pedro \& João Editores, 2010.

GERALDI, J. W.; GERALDI, C. M. G. A domesticação dos agentes educativos: Há uma luz no fim do túnel. In: Revista Inter.Ação. Revista da Faculdade de Educação da Universidade Federal de Goiás. Goiânia n. 1 jan./jun. 2012. Disponível em: <http://www.revistas.ufg.br/index.php/interacao/article/ view/18901/11250>. Acesso em 10 jan. 2013. 
KRAMER, S. Por entre as pedras: arma e sonho na escola. São Paulo: Ática, 2006.

Leitura e escrita como experiência - Notas sobre seu papel na formação. In:

ZACCUR, Edwirges (oOrg.). A magia da linguagem. Rio de Janeiro: DP\&A Editora, 1999.

LOPES, Ana Elisabete. GUSMÃO, Denise. PORTO, Cristina. Correspondências entrelaçadas: percursos de pesquisa com a fotografia. In: KRAMER, Sonia. NUNES, Maria Fernanda. CARVALHO, Maria Cristina. (Orgs.). Educação Infantil: formação e responsabilidade. Campinas: Papiruas, 2013.

LOPES, Amanda Teagno. Educação Infantil e registro de práticas. São Paulo: Cortez, 2009.

LARROSA, Jorge. Notas sobre a experiência e o saber da experiência. Tradução de J. W. Geraldi. In: Revista Brasileira de Educação, Jan/Fev/Mar/Abr, No 19, 2002. Disponível em: <http://www.anped.org.br/rbe/rbedigital/RBDE19/RBDE19_04_JORGE_LARROSA_BOND IA.pdf $>$. Acesso em 15 set. 2011.

LUCIO, Elizabeth Orofino. A palavra conta, o discurso desvela: saberes docentes na formação continuada de professores de leitura e escrita. Rio de janeiro,2016. Tese (Doutorado Educação) - FE/UFRJ. No prelo.

Tecendo os fios da Rede: o programa Pró-letramento e a tutoria na formação continuada de professores da educação básica. Rio de Janeiro, 2010. Dissertação (Mestrado Educação) - FE/UFRJ. Disponível em:

<http://www.educacao.ufrj.br/ppge/dissertacoes/Lucio_Elizabeth_Orofino_Dissertacao.pdf〉. Acesso em 25 mar. 2014.

LUCIO, E. O; VAREJÃO, J. D. S. F. O professor pesquisador e o professor alfabetizador nos espaços de formação continuada: olhares docentes sobre/para os alunos de classes populares das grandes metrópoles brasileiras. In: Anais.... Anais do XVI Encontro nacional de Didática e Práticas de Ensino - ENDIPE: FE/UNICAMP. Campinas, 2012. CDROM.

As raízes da alfabetização e os sentidos dos (novos) discursos sobre alfabetização na formação. In: Anais... I Congresso Brasileiro de Alfabetização da ABALF: FE/UFMG 2013, Belo Horizonte, 2013. CD-ROM.

. Leitura literária na escola pública brasileira: ato na formação continuada e no trabalho docente. Memoria... XII Congreso Latinoamericano para el Desarrollo de la Lectura y la Escritura y IV Foro Iberoamericano de literacidad y Aprendizaje:Puebla - México, 2013. Disponível em: <http://www.inaoep.mx/ cplorg/pdfs/m1.pdf〉. Acesso em 25 mar. 2014.

MELLO, Marisol Barenco de. Questões Bakhtinianas para uma heterociência humana. In: Teias v. $14 \cdot$ n. 31 $218-226 \bullet$ maio/ago. 2013.

MINAYO, M. C. S.; DESLANDES, S. F. e GOMES, R. (Orgs.). Pesquisa Social. Teoria, método e criatividade. 25 ed. Petrópolis: Vozes, 2007. 
MOTTA, Flavia Miller Naethe; CARVALHO, C. R.; Fernandes, Isabele. O Proinfantil e seus impactos na Baixada Fluminense: currículo, identidade e diferença. In: Currículo sem Fronteiras, v. 15, p. 667-683, 2015.

MOTTA, Flávia. De crianças a alunos: transformações sociais na passagem da educação infantil para o ensino fundamental. In: Educação e Pesquisa, v. 37, p. 157-173, 2011. 6, p. 18, 2005.

Reflexões sobre o respeito: contribuições para a pesquisa com crianças. In: Teias, v.

De crianças a alunos: a transição da Educação Infantil para o Ensino Fundamental. 1. ed. São Paulo: Cortez Editora, 2013.

PONZIO, Augusto. Encontro de palavras: o outro no discurso. São Carlos: Pedro \& João editores, 2012.

A escuta como lugar diálogo: Alargando os limites da identidade. São Carlos: Pedro \& João editores, 2012.

RAMOS, Lilian Maria Paes de Carvalho Ramos; PAULO, Luciana Hallak. (Orgs.). Memórias da pedagogia: relatos pioneiros do IM/UFRRJ. Seropédica: Ed. da UFRRJ, 2014.

ROJO, R.O. e MOURA, E. (Orgs.). Multiletramentos na escola. São Paulo: Parábola Editorial, 2012.

SAMPAIO, C.S. Alfabetização e formação de professores - Aprendi a ler (...) quando misturei todas aquelas letras ali. Rio de Janeiro: Wak, 2008.

Redes coletivas e (auto)formação docente: narrativas, experiências e (re)construção dos saberes e fazeres alfabetizadores. In: MORAES, D.Z.; LUGLI, R.S. (Orgs.). Docência, pesquisa e aprendizagem: (auto)biografias como espaço de formação/investigação. São Paulo: Cultura Acadêmica, 2010.

SAMPAIO, C. S. ; RIBEIRO, T. ; HELAL, I. ; CASTILHO, F.F. . Escola, formação e cotidianos: saberes e fazeres a partir de narrativas infantis. In: Teias, Rio de Janeiro, v. 12, 2011, p. 155-169.

SOBRAL, Adail. Ato/atividade e evento. In: BRAIT, BETH. (Org.). Bakhtin: conceitoschave. 4ed. São Paulo: Contexto, 2007, p. 11-36.

SOBRAL, Adail. U.; PERALTA, S. A. . Para uma formação dialógica do professor: reflexões a partir de um estudo de caso. In: Dialogia, UNINOVE, v. 8, 2009, p. 55-66.

SUARÉZ, D. H. Docentes, narrativa e investigación educativa - La documentación narrativa de las práticas docentes y la indagación pedagógica del mundo y las experiencias escolares. In: SVERDLICK, I. et al. (Comps.). La investigación educativa: Uma herramienta de conocimiento y de acción. Buenos Aires: Noveduc, 2007. 
${ }^{\text {i }}$ Professora bolsista do Institituto Multidisciplinar da Universidade Federal Rural do Rio de Janeiro. UNIRIO. Obteve o título de doutora pelo PPGE/UFRJ (2016), foi bolsista PSDE/CAPES na Universidade de Lisboa.

ii Refiro-me às greves docentes realizadas no Brasil, no ano de 2013, com amplo apoio social, e às respostas fundamentadas pedagogicamente pelos docentes para a não adesão aos pacotes instrucionais privados, comprados pelas Secretarias de Educação de São Gonçalo/ RJ, do Rio de Janeiro/RJ em 2010, Salvador/BA em 2013 e Aracaju/SE em 2014. No México, em setembro de 2013, os docentes lotaram a Praça principal da cidade, o Zócalo, lutando contra a privatização do ensino e as reformas educacionais. Manifestação similar ocorreu na cidade de Puebla no mesmo mês. Nesse período, eu me encontrava apresentando trabalho acadêmico no XII Congresso Latino-americano para o Desenvolvimento da Leitura e da Escrita e IV Fórum Ibero-americano de Letramento e Aprendizagem e presenciei as manifestações nesse país.

Durante todo o ano de 2014, realizei meu doutorado sanduíche em Portugal, na Universidade de Lisboa (UL), tempo em que participei do cotidiano da UL, da Escola Superior de Educação de Lisboa (ESELX) /Instituto Politécnico e do agrupamento de escolas Quintas de Marrocos.

Contexto em que a temática "professores em luto e em luta" é o mote das revindicações docentes e estudantis em Portugal, país que vive as consequências da reforma, com o fechamento de escolas, esvaziamento da profissão docente e "privatização" das universidades públicas.

O início do ano letivo de 2016, no contexto da Baixada Fluminense, é marcado pelo atraso de pagamentos e pela greve dos professores do município de Caxias, Nova Iguaçu e Mesquita, concomitantemente ao "aumento" de salário de vinte centavos aos docentes do município de Japeri.

iii O coletivo docente Caminhos foi constituído inicialmente por: Elizabeth Oliveira Dantas Alves, Mariza Linhares Alves Quintão, Ana Cristina de Melo Larceda, Mariza Linhares Alves Quintão, Fabiana Rosa de Mattos, Adenilce Isabel dos Santos e Luciane Martins de Sousa Cunha.

iv Responsabilidade e Responsividade são categorias Bakhtinianas em que são expostas a força dialogizadora e a ligação com os diversos campos da cultura humana: a ciência, a arte e a vida. Segundo o filósofo da linguagem, é preciso garantir o nexo entre elementos diferentes e compreendê-los em uma unidade de responsabilidade. Sendo assim, o existir não possui álibi e exige no momento do ato uma responsabilidade de resposta que apenas o próprio ator-autor, a partir de seu centro emotivo-evolutivo, é capaz de enunciar.

v Fragmento do portfólio da docente aluna Elizabeth Dantas da UFRRJ, professora da Rede Municipal de Queimados, apresentado como trabalho final da disciplina Alfabetização e Letramento, no primeiro semestre de 2015.

vi Para o filósofo da linguagem, o herói "vive de modo cognitivo e ético. Seu ato orienta-se em um acontecimento aberto e ético da vida ou no mundo da dado do conhecimento." A relação entre autor e herói é entre um Eu e um Outro, uma relação de alteridade, fundada na dialogia, em relação de responsividade.

viiO termo pesquisa-form $A C ̧ \tilde{A} O$ foi cunhado em meu estudo de tese, partindo da ideia de pesquisa-form $A C ̧ \tilde{A} O$ como produção de saberes e conhecimento, associada à proposta de escritura do que acontece no espaço de formação, na escola. O termo engloba a compreensão da formação enquanto ato e a certeza do professor como um intelectual (GRAMSCI, 1989), indo na "contramão" da concepção de formação modalizadora e escolarizada. Trata-se de uma luta política, tendo como defesa central uma via de formação sempre pensada com o professor ou futuro docente, a partir da realidade concreta do cotidiano escolar, de forma implicada, que possa trazer o pulsar da vida (MINAYO, 2007, p.12) na escola por meio da formação no discurso plasmado na veia docente.

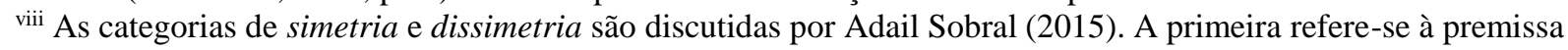
da igualdade entre os seres humanos, e a segunda diz respeito às posições distintas estabelecidas pelas relações sociais entre os participantes da interação.

${ }^{\text {ix }}$ Segundo Jorge Larrosa, a experiência é aquilo que nos passa, nos acontece, o que nos toca.

${ }^{x} \mathrm{O}$ termo "didocente" foi criado a partir da aglutinação das palavras discente e docente .

${ }^{\text {xi }} \mathrm{Na}$ perspectiva bakhtiniana, enunciado é o elemento da comunicação em relação indissociável com a vida. O autor afirma que enunciados são unidades reais de comunicação discursiva e que o discurso só se realiza/ se concretiza na forma de enunciados.

xii $O$ termo pesquisa-form $A C ̧ \tilde{A} O$ foi cunhado em meu estudo de tese, partindo da ideia de pesquisa-form $A C ̧ \tilde{A} O$ como produção de saberes e conhecimento, associada à proposta de escritura do que acontece no espaço de formação, na escola. O termo engloba a compreensão da formação enquanto ato e a certeza do professor como um intelectual (GRAMSCI, 1989), indo na "contramão" da concepção de formação modalizadora e escolarizada. Trata-se de uma luta política, tendo como defesa central uma via de formação sempre pensada com o professor ou futuro docente, a partir da realidade concreta do cotidiano escolar, de forma implicada, que possa trazer o pulsar da vida (MINAYO, 2007, p.12) na escola por meio da formação no discurso plasmado na veia docente. 